\title{
CONCEPÇÕES SUBJACENTES À PRÁTICA PEDAGÓGICA EM UMA PRÉ-ESCOLA ${ }^{1}$
}

\author{
José Moysés Alves*, Aldenise de Souza Maués", \\ Christianne Thatiana Ramos de Souza", Izabella Mendes Sant'Ana", \\ Líliam de Fátima Miranda Duarte", José Guilherme Wady Santos", Miguel Henrique Ribeiro Alves Júnior"
}

\begin{abstract}
RESUMO. Existem várias maneiras de se conceberem os objetivos da pré-escola e a forma como o professor deve conduzir as atividades. Como tais concepções se articulam na prática? Durante o ano letivo de 1996, observamos as atividades de uma turma de 22 pré-escolares (4 a 6 anos) da rede particular de ensino, registrando os procedimentos, os conteúdos e a duração de cada uma delas. Atividades estruturadas ocuparam cerca de metade do tempo em todos os meses. Dentre estas, as de cópia; pintura, recorte e colagem, desenho livre e dirigido foram as que ocuparam mais tempo. Conteúdos relacionados à escrita e à sociedade foram enfatizados, em detrimento daqueles relacionados à Matemática e, especialmente, à Natureza. Inferimos destas práticas uma concepção de pré-escola cujo objetivo é preparar para a alfabetização, concebida como a transmissão de um código de transcrição. A ênfase nos aspectos gráficos, no ensino das letras e números dificulta a inclusão desses aspectos em contextos de comunicação real.
\end{abstract}

Palavras-chaves: prática pedagógica; pré-escola; concepções subjacentes.

\section{IMPLICIT CONCEPTIONS IN PEDAGOCICAL PRACTICES AT ONE PRESCHOOL}

\begin{abstract}
There are several forms to conceive preschool aims and the manners that the teacher should conduct pedagogical activities. How such conceptions are articulated in practice? During one academic year we observed on a daily basis the activities developed by a group of 22 preschoolers (ages 4 to 6) attending a private school; the procedures used in, the contents of, and the duration of each activity were recorded. Structured activities occupied about half of the time each month. Among structure activities, copying, painting, cutting and pasting, free-style and directed drawing occupied most of the time. With regard to content, those related to Writing and Social Studies were given more emphasis than those related to Math and Sciences. We infer from those practices a conception of preschool whose goal is to prepare to literacy, which is conceived as transmission of a transcription code. The emphasis on graphic aspects in teaching letters and numbers hampers their inclusion in real communicative contexts, wasting the time that could be assigned to the teaching of Sciences.
\end{abstract}

Key words: Pedagogical Pratices; Preschool; Implicit Conceptions.

Existem várias maneiras de se conceberem os objetivos da pré-escola, a forma como o professor deve conduzir as atividades e como as crianças devem ser introduzidas à escrita, à matemática e aos conhecimentos básicos das ciências naturais e sociais.
O desenvolvimento cognitivo não está limitado ao contexto escolar, mas é nele, principalmente, que a criança entra em contato com o conhecimento sistematizado. Isto pode ter início na pré-escola, dependendo das funções que a ela sejam atribuídas.

1 Os autores agradecem ao CNPq, que apoiou o Projeto "Investigando o desenvolvimento cognitivo e intervindo na pré-escola" (Processo No. 524330/96-4), concedendo bolsa de Produtividade em Pesquisa para o primeiro autor e bolsas de Iniciação Científica para Aldenise Maués e Christianne Souza. Agradecem também ao PIPES/UFPA e PIBIC / UFPA, que concederam bolsas de Iniciação Científica para os demais autores. Uma versão preliminar do trabalho foi apresentada no XXVI Congresso Interamericano de Psicologia (São Paulo, 1997) com o título "Um contexto escolar do desenvolvimento cognitivo de pré-escolares".

* Professor doutor do Departamento de Psicologia Experimental da Universidade Federal do Pará.

Endereço para correspondência: José Moysés Alves, Trav. Mauriti, 3269 / 601A, Cep 66095-360, Marco, Belém-PA. E-mail: jmalves@amazon.com.br

\# Psicologo.

II Psicologo e mestrando do Programa de Pós-Graduação em Teoria e Pesquisa do Comportamento da Universidade Federal do Pará. 
Abramovay e Kramer (1985) discutem quatro funções da pré-escola, historicamente situadas. A "préescola guardiã", que cumpria exclusivamente a função de liberar as mães para o mercado de trabalho, atendendo apenas às necessidades de subsistência das crianças. A "pré-escola preparatória", que tinha por objetivo compensar as deficiências das crianças das classes populares, sua miséria, sua pobreza e a negligência de suas famílias, preparando-as para a alfabetização. A "préescola com objetivos em si mesma", que tinha por objetivo promover o desenvolvimento global e harmônico das crianças, mas que se isentava de estabelecer critérios mínimos de qualidade. E a "pré-escola com função pedagógica". Esta última concepção, defendida pelas autoras, considera que a pré-escola não visa, exclusivamente, à preparação para a alfabetização nos moldes tradicionais: ela "...toma a realidade e os conhecimentos infantis como ponto de partida e os amplia, através de atividades que têm um significado concreto para a vida das crianças e que, simultaneamente, asseguram a aquisição de novos conhecimentos" (p.35).

Dependendo de como se concebe a interação entre o processo de ensino-aprendizagem e o desenvolvimento, o professor da pré-escola pode assumir diferentes posturas na condução das atividades.

Vygotsky (1984) discute três concepções da interação entre $o$ processo de ensino-aprendizagem e o desenvolvimento, relevantes para esta reflexão. A primeira postula que o desenvolvimento precede a aprendizagem. Neste caso, grande ênfase é dada ao desenvolvimento espontâneo, e o ensino só se mostra frutífero quando encontra, no sujeito, estruturas capazes de assimilá-lo. Segundo Vygotsky, concebido desta maneira, o ensino se dirige para o passado, para aquelas funções que já se encontram amadurecidas. A segunda concepção postula que desenvolvimento é aprendizado. Neste caso grande ênfase é dada ao procedimento de ensino, em detrimento da atividade do sujeito e do conhecimento prévio que este possui sobre o assunto. Segundo Vygotsky, ao identificar os dois processos, a própria compreensão da interação entre ambos fica prejudicada. Por último, a concepção defendida pelo autor é a de que o processo de ensino-aprendizagem precede $\mathrm{o}$ desenvolvimento, criando zonas de desenvolvimento proximal. A instrução escolar faz com que o nível de desenvolvimento potencial das crianças, alcançado com a ajuda do professor ou dos colegas, tornese real. Ou seja, a interação social faz avançar o desenvolvimento. Neste caso, a instrução dirige-se para o futuro, para aquelas funções que estão em processo de amadurecimento.

A maneira como são organizadas as atividades escolares, seus conteúdos, procedimentos e duração, entre outros aspectos, também revelam concepções sobre a natureza dos conhecimentos em foco: o sistema de escrita alfabético; o sistema numérico decimal e os conceitos científicos elementares.

Segundo Ferreiro (1986), a escrita pode ser concebida como código de transcrição ou como sistema de representação. Por um lado, quando a escrita é concebida como um código de transcrição das unidades sonoras em unidades gráficas, sua aprendizagem é vista como a aquisição de uma técnica. A ênfase é dada aos aspectos gráficos, isto é, à qualidade dos traços, distribuição espacial das formas, orientação predominante e orientação dos caracteres individuais. $\mathrm{O}$ ensino se dirige, então, para o exercício da discriminação perceptiva nas modalidades audiovisuais. Por outro lado, quando a escrita é concebida como sistema de representação da linguagem, sua aprendizagem é vista como a apropriação de um novo objeto de conhecimento, ou seja, como uma aprendizagem conceitual que tem um desenvolvimento próprio. É dada ênfase aos aspectos construtivos, isto é, àquilo que se quis representar e aos meios utilizados para criar diferenciações; sendo central que o aluno compreenda a natureza da representação.

O sistema numérico decimal é um sistema de representação e, como tal, seu ensino pode enfatizar os aspectos gráficos ou os aspectos construtivos (Ferreiro, 1986).

Di Martino (1991) discute algumas concepções sobre o ensino de ciências, contidas em afirmações de professores do Ciclo Básico. Por Ciclo Básico a autora entende a política de requalificação da escola pública assumida pela Secretaria de Educação de São Paulo, desde 1984. Esta medida excluiu a possibilidade de os alunos serem reprovados ao final do primeiro ano do $1^{\circ}$ grau e veio acompanhada de investimentos na melhoria do trabalho nesta fase inicial da escolarização. Alguns professores concebem que o ensino de ciências é desnecessário para a formação da criança do Ciclo Básico e, portanto, dispensável. Outros professores não entendem o porquê da presença deste componente no currículo. Eles não contestam a presença de ciências no currículo, mas claramente colocam este aspecto em segundo plano, para quando sobra tempo. Nesta perspectiva, o ensino de ciências é descartável, não tendo um papel importante na formação da criança. Esses professores priorizam o ler, o escrever e o contar. Caso cheguem a trabalhar alguns conteúdos de ciências, os desenvolverão totalmente dissociados dos primeiros, num trabalho à parte e de uma forma, no mínimo, discutível. Outros professores se julgam despreparados para trabalhar os conteúdos de ciências, pois estão preocupados com a profundidade que acreditam que este ensino deva ter. Por último, existem aqueles que se preocupam com os alunos. Eles acreditam que o ensino 
de ciências envolve muita abstração e que os alunos do Ciclo Básico ainda não estão preparados para isto.

Estas concepções, provavelmente, não se aplicam apenas ao ensino das ciências naturais, mas também ao ensino das ciências sociais.

Todas estas concepções sobre diferentes aspectos da prática pedagógica na pré-escola podem ser estudadas separadamente. Trabalhos teóricos apontam algumas combinações possíveis entre uma forma e outra de conceber determinado aspecto. Por exemplo, a percepção da pré-escola com função pedagógica deve combinar-se com uma concepção do ensino da escrita como um sistema de representação (Kramer, 1985). A concepção de alfabetização como ensino conceitual deve combinarse com uma visão que privilegia a atividade autoestruturante do aluno (Ferreiro, 1986). A inclusão dos conteúdos de ciências deve estar associada a uma concepção de escrita como sistema de representação (Di Martino, 1991). Temos, por um lado, estudos teóricos que analisam as possíveis concepções sobre os objetivos da pré-escola e de como o professor deve conduzir as atividades neste nível de ensino e , por outro lado, temos estudos empíricos que se fundamentam, basicamente, nos relatos de professores. Na prática pedagógica as concepções se encontraram combinadas de diferentes maneiras, justificando perguntar como estas concepções se articulam na prática.

O presente estudo teve por objetivo descrever e analisar os tipos de atividades desenvolvidas durante um ano letivo para uma turma de crianças pré-escolares, levando em conta os conteúdos, procedimentos gerais e a duração das atividades, inferindo destas observações as concepções subjacentes e a forma como elas se articulam na prática.

\section{MÉTODO}

Participantes: Uma turma de pré-escola (Jardim II, segundo expressão usada na instituição) de uma escola da rede particular de ensino do centro da cidade de Belém, funcionando pela manhã. A turma era composta de 22 alunos, sendo 11 meninos e 11 meninas, com idades variando entre 4 e 6 anos.

Procedimento de coleta: seis observadores, alunos do terceiro ano do Curso de Psicologia da Universidade Federal do Pará, se revezaram numa escala de rodízio, abrangendo todos os dias da semana, durante o ano letivo de 1996. Eles anotavam todas as atividades realizadas a cada dia, levando em conta os conteúdos, procedimentos gerais e duração. Poucos dias deixaram de ser observados a cada mês, considerando-se os feriados nacionais, estaduais, municipais e próprios da escola. No total, foram observados 127 dias de aula. As observações focalizaram apenas as atividades orientadas ou que dependiam de uma intervenção direta da professora, as quais chamamos de atividades estruturadas. Não foram objeto de observação sistemática as atividades que não dependiam de uma intervenção direta da professora, como as brincadeiras, as quais chamamos de atividades não-estruturadas. Não significa, absolutamente, que consideramos tais atividades não-estruturadas sem importância para o desenvolvimento cognitivo, mas significa que o foco da investigação estava nos tipos de intervenções feitas pela professora.

Procedimento de análise: Os registros diários foram analisados, classificando-se os tipos de atividades que possuíam um procedimento geral semelhante, ainda que neles pudessem ser trabalhados conteúdos relacionados a diferentes disciplinas. Os tipos de atividades encontradas foram: desenho livre; desenho dirigido; pintura, recorte e colagem; cópia; rodinha (segundo expressão usada na escola); músicas, dança e teatro; história e piscina, para citar as mais frequientes. Em seguida, foram agrupados os conteúdos específicos de cada tipo de atividade trabalhados no mês, totalizando-se o tempo ocupado por cada tipo de atividade. A partir desta análise, agruparamse os conteúdos relacionados com cada disciplina (linguagem escrita, matemática, natureza e sociedade) pelos tipos de atividades, totalizando-se a duração das atividades em cada disciplina, a cada mês.

\section{RESULTADOS}

Em primeiro lugar, calculou-se a porcentagem de tempo ocupada por cada um dos tipos de atividades realizados a cada mês, somando-se os minutos registrados para cada tipo de atividade e dividindo-se pelo total de minutos observados no mês.

Em todos os meses, exceto junho, atividades nãoestruturadas ocuparam mais de $40 \%$ do tempo e, nos meses de março e outubro, este percentual foi superior a $50 \%$. Neste tempo, que ocorria principalmente no início e no final das atividades diárias, as crianças, por sua livre iniciativa, brincavam com os brinquedos que traziam de casa ou que estavam disponíveis na sala; com jogos; com massa de modelar; desenhavam; folheavam livros de histórias ou brincavam no parque.

Desenho livre; desenho dirigido; pintura, recorte e colagem e cópia, cuja ênfase repousava no exercício da coordenação viso-motora, foram atividades realizadas todos os meses e ocuparam, juntas, um percentual superior a $30 \%$, em cada mês.

A rodinha, na qual eram dadas as explicações e eram feitas as conversas coletivas; as histórias (contadas e algumas vezes interpretadas e dramatizadas) e as músicas, danças e teatro, também foram atividades realizadas em 
todos os meses, ocupando um percentual de tempo sempre inferior a $20 \%$ do tempo total observado.

As outras atividades (passeio pela escola; blocos lógicos; cinema; banco; vivência das profissões; tirar fotografias; visita ao parque zoobotânico; ligar letras com palavras; montar palavras; ditado; somar e subtrair; trabalhos com sucata; eleições simuladas e escrever carta) ocorreram em apenas um ou dois meses, ocupando tempo reduzido.

Em segundo lugar, calculou-se a porcentagem de tempo ocupada por atividades relacionadas às disciplinas: escrita, matemática, natureza e sociedade.

O tempo total analisado corresponde a cerca de $30 \%$ do total de tempo observado, pois excluiu-se o tempo das atividades não-estruturadas, como também o tempo do desenho livre, da piscina e das histórias que não estavam diretamente relacionados às disciplinas. Do total de tempo ocupado por estas atividades (9198 minutos), $40 \%$ relacionavam-se diretamente à escrita, $39.74 \%$ à sociedade, $17.22 \%$ à matemática e apenas $3.04 \%$ do tempo foi ocupado por atividades relacionadas à natureza.

Em terceiro lugar, calculou-se a porcentagem de tempo ocupada por cada tipo de atividade, em cada disciplina.

Entre as atividades que envolviam a escrita, a que ocupou mais tempo foi a de cópia $(65.56 \%$ do tempo ocupado pela disciplina). Os conteúdos destas cópias foram: as vogais; encontros vocálicos; famílias silábicas das letras "v", "p", "m" e "n"; palavras e frases formadas com elas, por exemplo: "Papai viu o pipo", "A ave voa"; e frases relacionadas com as datas comemorativas como "A árvore é nossa amiga", "O Natal é bonito". A segunda atividade com maior duração foi a rodinha (13.37\%), onde eram explicadas as formas das letras (maiúsculas e minúsculas; cursiva e de forma); os encontros vocálicos; solicitava-se que as crianças dissessem palavras iniciadas com uma letra ou sílaba; era feita a leitura de palavras e rótulos; era mostrado como montar palavras a partir de sílabas, etc. Nas atividades de pintura, recorte e colagem (6.66\% do tempo das atividades de escrita), as crianças eram solicitadas a pintar e recortar letras, o que ocorreu nos primeiros meses do ano. Nos últimos meses do ano, as crianças foram solicitadas a montar palavras com letras e sílabas (5.03\%) e fazer ditado de palavras soltas (5.44\%). Atividades que oportunizavam a escrita espontânea em situação comunicativa: escrever carta (1.63\%) ou escrever história $(0.81 \%)$ foram pouco freqüentes e só ocorreram ao final do ano.

Entre as atividades relacionadas à matemática, notouse que, como na escrita, estas foram mais freqüentemente de cópia (37.63\% do tempo total ocupado pela disciplina). As crianças copiaram: linhas curvas e retas, formas geométricas, data, números e adições. Nas atividades de pintura, recorte e colagem (22.73\%) foram trabalhados, além da forma de cada número, a contagem de objetos desenhados e a escrita dos números correspondentes ou o colar palitos e pedaços de papéis correspondentes a um número dado. Na rodinha $(18.94 \%)$ era feita a leitura do calendário, contagem; eram dadas explicações sobre o conceito de grande e pequeno, e explicações sobre adição e subtração. No desenho dirigido $(9.97 \%)$ foram trabalhados os conceitos de grande e pequeno e o desenho de objetos em quantidades correspondentes a números dados. Somar e subtrair $(5.05 \%)$ só ocorreu no mês de novembro. As demais atividades ocorreram com um tempo muito reduzido.

As atividades relacionadas à sociedade foram mais freqüentemente de pintar, recortar e colar $(27.50 \%$ do tempo ocupado pela disciplina); desenhar (25.58\%); e músicas e danças $(22.11 \%)$, quase sempre com temas relacionados às datas comemorativas como Páscoa, dia da árvore, dia do índio, dia das mães, festas juninas e Natal. Ocorreram, com duração menor, oportunidades de as crianças copiarem frases relacionadas a estas datas (7.11\%) e receberem explicações ou conversarem sobre o significado das mesmas (Rodinha $=6.62 \%$ ). Ocorreram algumas oportunidades nas quais as crianças vivenciaram situações socioculturais, como a vivência das profissões e as eleições simuladas, mas estas ocuparam uma porcentagem de tempo muito reduzida.

Nas atividades relacionadas à natureza, que ocuparam apenas cerca de $3 \%$ do tempo das atividades relacionadas às disciplinas, foram trabalhados os assuntos: partes do corpo humano, animais domésticos e selvagens, partes da árvore e como a planta respira e bebe água. Além disso, as crianças fizeram um passeio a um parque zoobotânico.

\section{DISCUSSÃO}

Os resultados do presente estudo mostraram que o tempo das atividades dos pré-escolares estava dividido, quase na metade, entre atividades estruturadas e atividades não-estruturadas.

Aspectos importantes do desenvolvimento motor, social, afetivo e cognitivo dos pré-escolares estavam em desenvolvimento, durante as atividades não-estruturadas. Eles interagiam com os colegas, brincavam de faz-deconta, modelavam massa, brincavam no parquinho, etc. Mas estas atividades não foram alvo de observações sistemáticas no presente estudo.

Só as atividades estruturadas foram objeto de análise. Esta análise considerou a duração dos tipos de atividades em cada disciplina e mostrou que foram enfatizados as atividades perceptomotoras e os aspectos gráficos da escrita e dos números. O trabalho em torno de datas 
comemorativas ocupou quase a metade do tempo destas atividades, enquanto os trabalhos relacionados ao conhecimento do mundo natural foram pouco freqüentes.

A ênfase nos exercícios perceptomotores, por um lado, podem ser importantes na medida em que ajudam a criança a ter disciplina, num período em que os centros de discriminação e inibição do sistema nervoso começam a amadurecer (Galvão, 1995). Por outro lado, estes exercícios enfatizavam os aspectos gráficos das letras e números, em detrimento do trabalho com os aspectos construtivos destes objetos de conhecimento.

Podemos dizer que as atividades estruturadas visavam, sobretudo, à preparação para a alfabetização e para a aprendizagem dos números, concebidos mais como códigos do que como sistemas de representação. A ênfase era dada ao exercício da coordenação motora fina (desenhos dirigidos; pintura, recorte e colagem; cópia). Além disso, estes conhecimentos foram ensinados como uma técnica, através da qual se pretendia o domínio progressivo e cumulativo da mecânica neles envolvida: o desenho das letras e dos números; a associação som/grafia; a adição de letras para formar sílabas e destas para formar palavras, etc.

No contexto da instrução sobre a escrita, fica clara a concepção da interação entre desenvolvimento e instrução que identifica os dois processos. Isso poderia ser expresso dizendo-se que a criança se desenvolve seguindo os passos dos procedimentos utilizados pelo professor - por exemplo, que ela aprende a ler dominando primeiro a família do "v" depois a do "p", e assim sucessivamente, porque esta foi a maneira como o professor introduziu o conteúdo. As oportunidades que as crianças tiveram para escrever espontaneamente foram raras. A professora considerava inadequado oferecer às crianças tais atividades, já que elas não conheciam todo o alfabeto. Parece ser ignorado o fato de que as crianças constroem hipóteses sobre a linguagem escrita e que recriam aspectos importantes do sistema, mesmo antes de conhecer o valor convencional das letras. Ou seja, os aspectos construtivos, aquilo que a criança quis representar e as formas que usou para criar diferenciações, são deixados de lado, revelando uma concepção de escrita como um código de transcrição de unidades sonoras em unidades gráficas, associada, como vimos, a uma concepção que identifica o processo de ensino-aprendizagem e o desenvolvimento.

A preocupação em preparar para a alfabetização, concebida como o ensino de um código de transcrição, com ênfase nos aspectos gráficos, dificulta sua integração às outras disciplinas. Se as crianças devem ler e escrever com as famílias silábicas que estão sendo trabalhadas, como podem escrever sobre suas observações e pesquisas?. A escrita, desta forma, fica empobrecida de outras das suas funções sociais para servir a uma função meramente escolar. Como conseqüência, a atividade de escrever pode passar a ter pouco significado para a criança.

A ênfase nos aspectos perceptomotores também aconteceu no trabalho em torno das datas comemorativas. Tais atividades podem ser adequadas para a faixa etária das crianças, uma vez que, participando destas datas, ainda que, na maior parte do tempo, recortando, colando, pintando e copiando, elas estão tomando parte de eventos importantes para a cultura de seu grupo social. Só uma análise mais detalhada da interação professor-alunos e entre alunos poderia dizer se e como, durante tais atividades, as relações interpessoais estavam sendo tematizadas.

A integração dos conteúdos das disciplinas tem sido defendida tanto por autores preocupados com o processo de alfabetização quanto pelos que estão preocupados com o ensino de ciências (por exemplo, Di Martino , 1991; Moraes, 1995; Ferreiro, 1996).

A proposta de organização dos conteúdos na préescola em torno de "temas geradores", feita por Kramer (1994), parece interessante para garantir a integração entre as disciplinas. Nesta proposta, a partir de temas de interesse das crianças, são trabalhados conteúdos das diversas áreas. Outra possibilidade é a organização do currículo por projetos de trabalho, em que a escrita e os números são instrumentos usados nas diversas pesquisas que os alunos fazem (por exemplo, Hernández e Ventura, 1998). O Referencial Curricular Nacional para a Educação Infantil (MEC/SEF, 1998), que incorpora aspectos importantes da experiência internacional sobre educação infantil, entre outras orientações didáticas, também indica os projetos de trabalho.

Uma das experiências de educação infantil mais bem sucedidas do mundo e comentada por vários autores (Ghedini, 1994; Faria, 1994, 1995; Edwards, Gandini e Forman, 1999) é a de Reggio Emilia, no norte da Itália. Lá também os pré-escolares trabalham em projetos. Eles solucionam problemas cooperativamente, em pequenos grupos de, no máximo, cinco crianças. O currículo é informal. Há um foco sistemático sobre a representação simbólica. Cada criança é percebida como única e protagonista do seu próprio crescimento. Os professores, além das funções tradicionais de promover as aprendizagens das crianças, manejar a sala de aula, preparar o ambiente, oferecer incentivo e orientação, comunicar com outras pessoas importantes (pais, colegas, administradores, público em geral) e buscar o crescimento profissional, engajam-se politicamente para defender a causa da educação pública precoce e fazem pesquisas sistemáticas sobre o trabalho diário em sala de aula, visando difusão profissional, planejamento do currículo e desenvolvimento do professor. Entre muitas 
outras características interessantes, destaca-se a estreita relação família-comunidade nas escolas de Reggio Emilia.

As concepções de criança; aprendizagem cooperativa; currículo informal; papel do professor e sua formação continuada e a relação escola-comunidade contrastam com a realidade da pré-escola observada no presente estudo. Acreditamos que o cenário que analisamos ainda é semelhante à realidade da maior parte das escolas brasileiras.

Neste contexto, a concepção de alfabetização parece ter um papel central no planejamento de atividades para o último ano da pré-escola. Concebida como o ensino de uma técnica, com ênfase nos aspectos gráficos, determina, por um lado, todo um período preparatório que, desconsiderando os conhecimentos prévios e as hipóteses das crianças, visa, principalmente, o treino de discriminação percepto-motora. Por outro lado, dificulta a inclusão da escrita em contextos de comunicação real, inclusive na leitura e escrita do mundo social e natural. Concebidos como um ensino conceitual, de novos objetos de conhecimento, com ênfase nos aspectos construtivos, os sistemas de representação (desenho, escrita, números, etc.) podem ser aprendidos de uma maneira informal, aperfeiçoando-se aos poucos, dentro de contextos significativos.

Mudanças de concepções e práticas pedagógicas passam, necessariamente, pela formação do professor, especialmente aquela que se realiza em seu ambiente de trabalho, como reflexão sobre a prática (Hernández, 1998).

O presente estudo fez parte do projeto de pesquisa Investigando o desenvolvimento cognitivo e intervindo na pré-escola que tinha por objetivos: a) observar, diariamente, as atividades oferecidas a esta turma de préescolares; b) documentar a evolução dos conhecimentos das crianças em várias áreas (narrativas, desenhos, escrita, matemática, conceitos científicos e jogo de dominó) e c) informar e discutir com a professora da turma e outros técnicos responsáveis pelo planejamento escolar, os resultados destas observações e avaliações. A nossa expectativa era a de que, ao mostrar para a professora, periodicamente, os resultados da avaliação de seus alunos e das observações em sala de aula, isto poderia levá-la a reformular o planejamento e execução das atividades o que, por sua vez, teria efeitos nos resultados das avaliações e observações subsequentes. Isto não aconteceu ou não se tornou visível aos nossos instrumentos de observação. Acreditamos que a estratégia utilizada não foi suficiente para promover melhoria das práticas docentes na pré-escola.

Pesquisas futuras poderiam se preocupar em obter o relato da professora sobre suas concepções ao longo do processo; focalizar mais detalhadamente as interações professor-alunos e entre alunos; levar em conta o desenvolvimento sócio-afetivo, tão importante quando se pensa o currículo para esta faixa etária e considerar outras estratégias para promover mudanças nas concepções e práticas de professores. Além do tempo que um professor trabalha de uma determinada forma, existem condicionantes institucionais que contribuem para que estas concepções e práticas se perpetuem.

\section{REFERÊNCIAS BIBLIOGRÁFICAS}

Abramovay, M. \& Kramer, S. (1985) O rei está nu: um debate sobre as funções da pré-escola. Cadernos CEDES. 9, p 27-38.

Brasil/mec/sef. (1998) Referencial Curricular Nacional para a Educação Infantil. (3 Vols.). Brasília.

Di Martino, E.R. (1991) O Ciclo Básico e o Ensino de Ciências: uma tomada de consciência. Em: São Paulo (Estado) Secretaria da Educação. Coordenadoria de Estudos e Normas Pedagógicas. A Criança e o Conhecimento: retomando a proposta pedagógica do ciclo básico. São Paulo: SE / CENP (Projeto IPÊ)

Edwards, C.; Gandini, L. \& Forman, G. (Orgs.) (1999) As cem linguagens da criança: a abordagem de Reggio Emilia na educação da primeira infância. Porto Alegre: Artes Médicas.

Faria, A. L. G. (1994) Impressões sobre as creches no norte da Itália: bambini si diventa. Em: F. Rosemberg \& M. M. Campos. Creches e pré-escolas no hemisfério norte. (pp. 211-232). São Paulo: Cortez e Fundação Carlos Chagas.

Faria, A. L. G. (1995) Da escola materna à escola da infância: a préescola na Itália hoje. Cadernos CEDES, 37, 63-67.

Ferreiro, E. (1986) Reflexões sobre Alfabetzação. São Paulo: Cortez/Autores Associados.

Ferreiro, E. (1996) Com todas as letras. São Paulo: Cortez.

Galvão, I. (1995)_Henri Wallon: uma concepção dialética do desenvolvimento infantil. Petrópolis: Vozes.

Ghedini, P. O. (1994) Entre a experiência e os novos projetos: a situação da creche na Itália. Em: F. Rosemberg, \& M. M Campos (Org.), Creches e pré-escolas no hemisfério norte. (pp. 189-210). São Paulo: Cortez e Fundação Carlos Chagas.

Hernández, F. \& Ventura, M. (1998) A Construção do Currículo por Projetos de Trabalho. Porto Alegre: Artes Médicas.

Hernández, H. (1998). A importância de saber como os docentes aprendem. Pátio 1(4), .9-13.

Kramer, S. (Coord.) (1994) Com a pré-escola nas mãos: uma alternativa curricular

para a educação infantil. São Paulo: Ática.

Moraes, R. (1995) Ciências para as séries iniciais e alfabetização. Porto Alegre: SAGRA-DC LUZZATO

Vygotsky, L.S. (1984) A Formação Social da Mente. São Paulo: Martins Fontes.

Recebido em 24/07/2001

Revisado em 10/10/2001

Aceito em 18/10/2001 
